\title{
A rupture model of the 2011 off the Pacific coast of Tohoku Earthquake
}

\author{
Charles J. Ammon ${ }^{1}$, Thorne Lay ${ }^{2}$, Hiroo Kanamori ${ }^{3}$, and Michael Cleveland ${ }^{1}$ \\ ${ }^{1}$ The Pennsylvania State University, University Park, Pennsylvania 16802, USA \\ ${ }^{2}$ University of California Santa Cruz, Santa Cruz, California 95064, USA \\ ${ }^{3}$ California Institute of Technology, Pasadena, California 91125, USA
}

(Received April 7, 2011; Revised May 13, 2011; Accepted May 18, 2011; Online published September 27, 2011)

\begin{abstract}
The 11 March 2011 Tohoku Earthquake ruptured the interplate boundary off-shore of east Japan, with fault displacements of up to $40 \mathrm{~m}$ and a rupture duration of 150-160 s. W-phase inversion indicates a moment of $3.9 \times 10^{22} \mathrm{~N} \mathrm{~m}\left(M_{\mathrm{w}} 9.0\right)$ and a centroid time of $71 \mathrm{~s}$. We invert teleseismic $P$ waves and broadband Rayleigh wave observations with high-rate GPS recordings from Japan to characterize the rupture. The resulting rupture model begins with a steady increase of moment rate for the first $80 \mathrm{~s}$, and a rupture speed of $1.5 \mathrm{~km} / \mathrm{s}$. Then the rupture expands southwestward at a speed of about $2.5 \mathrm{~km} / \mathrm{s}$. The model's primary slip is concentrated updip from the hypocenter, with significant displacement extending to the trench. The seaward location of large slip is consistent with estimates of the tsunami source area from regional and remote tsunami observations. The region with large slip is approximately $150-\mathrm{km}$ wide by $300-\mathrm{km}$ long, which is relatively compact compared with the $200-\mathrm{km}$ wide, $500-\mathrm{km}$ long aftershock region. The model's initial updip rupture expansion and the location of most slip updip of the hypocenter differs from $P$-wave array back-projections, which map high-frequency radiation along the downdip of the hypocenter, closer to the coast.
\end{abstract}

Key words: Great earthquakes, earthquake rupture processes, broadband seismology.

\section{Introduction}

The great 11 March 2011 Tohoku Earthquake ruptured a large segment of the Pacific-North American (Okhotsk) plate boundary off the coast of northeastern Japan. This boundary has hosted large and deadly earthquakes in the past, but the 2011 event is the largest $\left(M_{\mathrm{w}} 9.0-9.1\right)$ in the recent history of Japan, and one of the five largest earthquakes of the modern era. Convergence across the boundary is close to trench-perpendicular at roughly $92 \mathrm{~mm} / \mathrm{yr}$ (DeMets et al., 2010). The earthquake excited a large tsunami that devastated coastal communities in Japan. The earthquake is likely to be one of the most important seismic events recorded thus far because of the relatively long record of information on earthquakes in the region, and because of the extensive investment by Japan in geophysical observational facilities that recorded diverse signals from the event with unprecedented detail.

The Tohoku sequence began at 02:45:20.28 UTC on 9 March 2011, when an $M_{\mathrm{w}} 7.2$ (USGS) to 7.5 (globalcmt.org) underthrusting foreshock located at $38.42 \mathrm{~N}$, $142.83 \mathrm{E}$ struck just to the north of the subsequent great earthquake epicenter. Depth estimates for the initiation of the major foreshock and the great earthquake are $\sim 30 \mathrm{~km}$. Aftershocks of the 9 March 2011 foreshock spread to the north, but several of the larger events appear to have migrated towards the eventual nucleation region of the 11 March 2011 mainshock, which struck at 05:46:24.51 UTC

Copyright (c) The Society of Geomagnetism and Earth, Planetary and Space Sciences (SGEPSS); The Seismological Society of Japan; The Volcanological Society of Japan; The Geodetic Society of Japan; The Japanese Society for Planetary Sciences; TERRAPUB.

doi:10.5047/eps.2011.05.015 at $38.30 \mathrm{~N}, 142.34 \mathrm{E}$ (USGS). Moment tensor inversion of 123 W-phase recordings (Kanamori and Rivera, 2008) from 71 global seismic stations indicates a mainshock seismic moment of $3.9 \times 10^{22} \mathrm{~N} \mathrm{~m}\left(M_{\mathrm{w}} 9.0\right)$, with small non-double couple component and a best nodal plane striking $202^{\circ}$, dipping $12.9^{\circ}$, a rake of $92.5^{\circ}$, and a 71 s centroid time shift. The great event initiated a vigorous aftershock sequence that included an $M_{\mathrm{w}} 7.9$ underthrusting aftershock near the southern end of the rupture approximately $28 \mathrm{~min}$ utes later (06:15:40.88 UTC, 36.18N 141.17E; USGS); ten minutes after that, (06:25:50.79 UTC) a large, $M_{\mathrm{w}}$ 7.7, extensional faulting earthquake occurred in the outer rise region $(38.06 \mathrm{~N}, 144.60 \mathrm{E})$ of the Pacific plate. As of $25 \mathrm{March}$ 2011 , the continuing aftershock sequence has included 3 aftershocks with magnitudes of 7.0 or larger, nearly 40 with magnitudes between 6.0 and 7.0, and over 350 events in the magnitude range from 5.0 to 6.0 .

\section{The Observations}

To estimate the slip and rupture properties of the earthquake, we modeled teleseismic $P$ waves and short-arc Rayleigh wave $\left(R_{1}\right)$ relative source time functions (RSTF), and three-component high-rate (30-second sample interval) GPS (hrGPS) ground motion time series. Teleseismic $P$ and $R_{1}$ waveforms were obtained from the Federation of Digital Seismic Networks through the Incorporated Research Institutions for Seismology (IRIS) data center. The hrGPS data were made available by JPL, using GPS recordings collected by the Geospatial Information Authority (GSI) of Japan. Instrument effects were removed from the $P$ waveforms to produce displacements seismograms, and data were selected to provide a relatively uniform sam- 


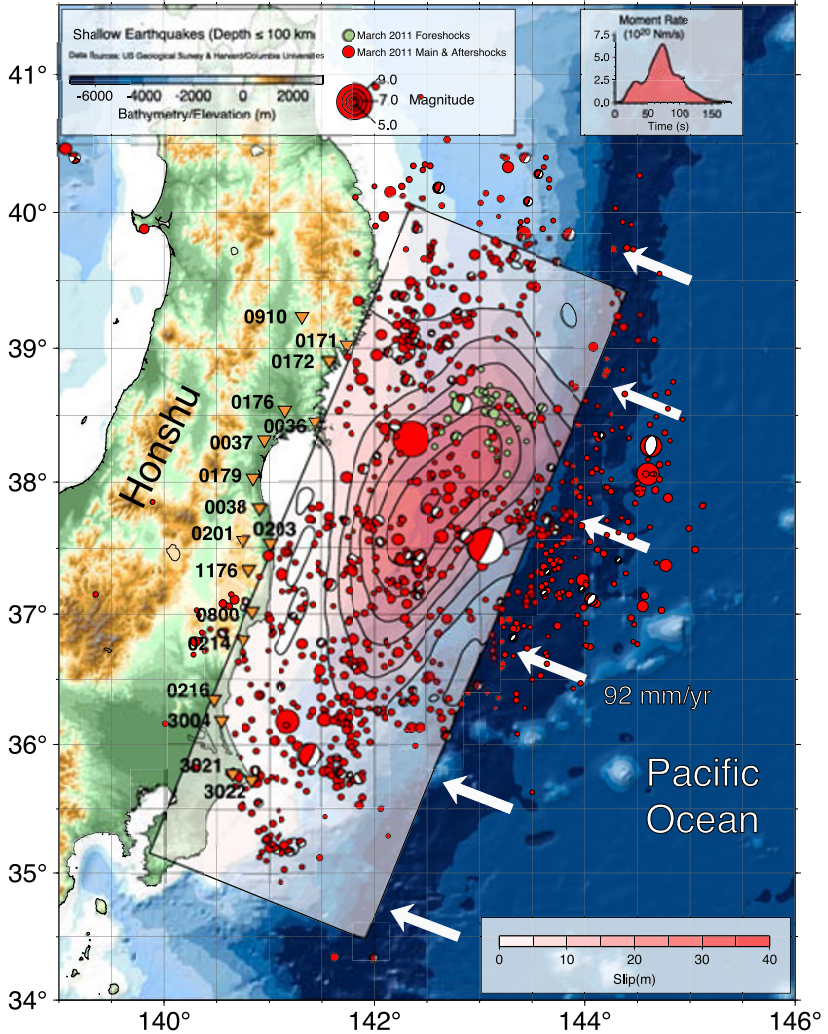

Fig. 1. Map showing foreshocks, aftershocks, MORVEL model plate motions, rupture-model slip contours, and the locations of hrGPS stations (inverted triangles) used in to construct the model. Focal mechanisms are shown at the GCMT centroid.

pling as a function of azimuth. The hrGPS observations were provided in units of displacement and, of the numerous stations available, a subset of signals from along the coast (closest to the rupture, Fig. 1) was selected and utilized for this preliminary work.

The $R_{1}$ RSTFs were estimated from the mainshock observations using the $M_{\mathrm{w}} 7.2$ foreshock signals as empirical Green functions (e.g., Ammon et al., 1993). We isolated the $R_{1}$ signals with a wide group velocity window, and deconvolved the signals using an iterative time-domain procedure based on the method of Kikuchi and Kanamori (1982). We convolved each signal with a low-pass Gaussian filter to reduce short-period noise in the resulting time series. The resulting time series isolate the differential effects of the larger and smaller event ruptures, with accurate estimation of the main event properties for periods longer than about $30 \mathrm{~s}$. Use of theoretical Green functions results in similar $R_{1}$ source functions, but aspherical effects are more directly accounted for using the EGF approach. For many large earthquakes, $R_{1}$ STFs show strong directivity patterns because the phase velocity of the $R_{1}$ signals is relatively close to the rupture speed, enhancing directivity effects in the signals. For predominantly along-strike unilateral or bilateral ruptures the azimuthal directivity patterns are quite simple and can be analyzed in a straightforward way (e.g., Furlong et al., 2009; Lay et al., 2010b). In the case of the 2011 event, no simple azimuthal pattern in the $R_{1}$ RSTFs was observed, suggesting that rupture propagation was sig- nificant in at least two, non-parallel directions.

\section{The Rupture Model}

We modeled the observations using a least-squares localsearch algorithm that is designed to construct the broad features in the rupture first, then refine the broad features by adding detail as the search progresses (Ammon et al., 2005, 2006). For each step in the search, part of the model is randomly perturbed, the effect on the fits to the observations is assessed, and if the fits improve, we keep the new model, otherwise we try another perturbation. The rupture speed is specified during each search, and numerous searches are used to explore the sensitivity to the assumed rupture kinematics. Time functions in the search are restricted to a set of half-cosine shapes (Ji et al., 2002) that range in duration from 20 to $40 \mathrm{~s}$, in $4 \mathrm{~s}$ increments.

We used teleseismic $P$ waves only and a non-negative least squares algorithm to initially explore the likely rupture speeds and found that a slow initial rupture expansion followed by a faster expansion resulted in relatively simple slip distributions and good fits to the data. We adopted a slow initial rupture speed $(1.5 \mathrm{~km} / \mathrm{s})$ with which the rupture expands to a distance of $100 \mathrm{~km}$ from the hypocenter, after which the rupture propagates outward with increased speed of $2.5 \mathrm{~km} / \mathrm{s}$. Our results are generally consistent for small $(0.5 \mathrm{~km} / \mathrm{s})$ variations in these parameters — as always, a faster rupture speed spreads the moment further over the fault, a slower rupture speed results in a more compact pattern and larger estimates of slip (Lay et al., 2010c). We included $39 P$ waveforms, $31 R_{1}$ RSTFs, and 15 threecomponent hrGPS signals. We initiated the rupture at the USGS hypocenter, aligned the observed and predicted $P$ waveforms by picking the $P$ onsets, shifted several of the $R_{1}$ RSTFs to improve alignments, and used absolute time to fit the hrGPS signals. We chose a strike of $202^{\circ}$, consistent with the $\mathrm{W}$-phase solution, to align the top of the model with the local trend of the trench, and assumed a dip of $12^{\circ}$, which is within the range $\left(10-14^{\circ}\right)$ estimated by various early long-period point-source inversion efforts. We fixed the rake at $85^{\circ}$, which is again consistent with the available long-period point-source estimates of the average rupture process. $P$ wave only solutions with non-negative least squares suggest minor variations in rake over the fault plane, but these are not well resolved. Future inversions can include variations in rake but that approach becomes more complicated when working with the $R_{1}$ RSTFs, which have been estimated using Green functions for a single rake. Perhaps the most complicated part of modeling multiple, complementary data is interpreting the results from data modeled with different approaches and different earth model parameterizations. The $P$ waves were modeled using a $2 \mathrm{~km}$ thick water-layer over a halfspace with a $P$-wave speed of $6.2 \mathrm{~km} / \mathrm{s}$. Clearly a half-space is a first order approximation to the lateral variation in the structure over the great event source region. The $R_{1}$ STFs are modeled using the true earth model for the foreshock location, since we used an empirical Green Function approach. The geodetic observations were modeled using spheroidal mode summation for the anisotropic PREM structure with all modes up to $50 \mathrm{mHz}$ (Luis Rivera, personal communication, 2011). 


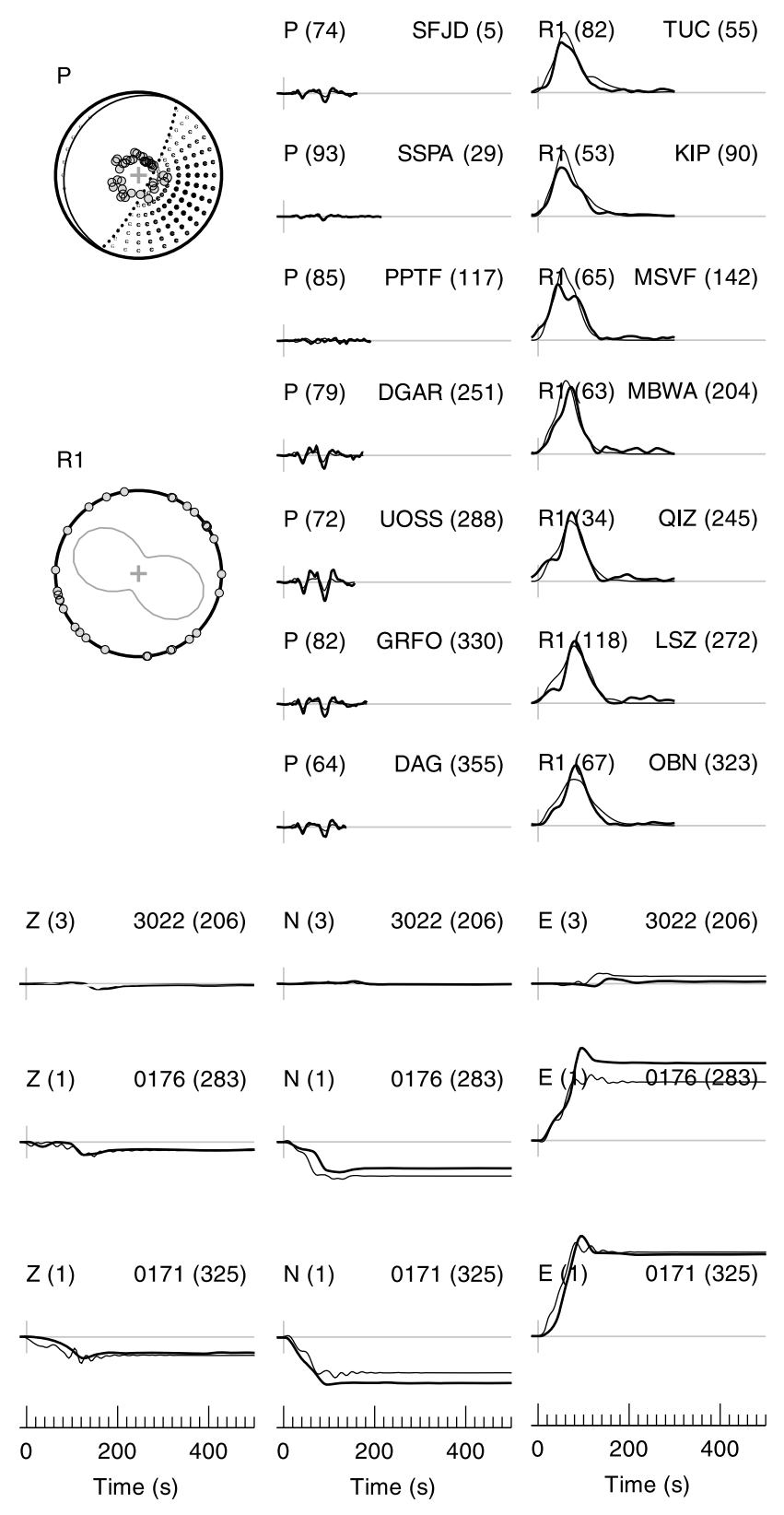

Fig. 2. Sample of the observations and predictions used and resulting from the fault model inversion. The focal mechanisms show the full distribution of the $P$ waveforms and $R_{1}$ RSTFs used along with appropriate radiation patterns. hrGPS station locations are shown in Fig. 1. For each waveform, the thick line identifies the observation, the thin line the prediction. The wave type or ground displacement component and distance in degrees are listed above to the left of each waveform pair, Z is for vertical, $\mathrm{N}$ is for north, and $\mathrm{E}$ is for east. The station ID and the azimuth are listed to the upper right of each waveform pair.

The preliminary rupture model slip distribution is shown on the map in Fig. 1. Sample fits to all three data types are shown in Fig. 2 (all fits cannot be shown due to space limitations). Although the model is parameterized in terms of source strength, or seismic moment, we convert those values to slip using the shear modulus from the $P$-wave halfspace $(34.6 \mathrm{GPa})$, and the subfault areas $\left(15 \times 15 \mathrm{~km}^{2}\right)$. The slip distribution shown is thus directly proportional to the seismic moment distribution, and is a first order estimate of slip over the rupture area. As always, conversion to slip in regions that may have substantially different shear modulus, as may exist at depth or under the toe of the wedge is problematic, as the estimated seismic moment distribution can itself be affected by changing the source rigidity structure (see Lay et al. (2011a) for a discussion of these issues). This model is smooth and does not reproduce all the details in the $P$ waveforms, but provides reasonable fits to the long-period $R_{1}$ RSTFs and the hrGPS signals (Fig. 2). The model is dominated by a region of large moment immediately up-dip of the hypocenter (Fig. 1), a feature shared with $P$-wave only inversions. The peak slip is just over $40 \mathrm{~m}$, and occurs about $30 \mathrm{~km}$ trenchward and slightly south of the hypocenter. The slip spatial centroid is located $40 \mathrm{~km}$ south along strike and about $35 \mathrm{~km}$ up-dip. $P$-wave only inversions using layered velocity structures predict increased slip at the shallowest depths (Lay et al., 2011a). We also inverted the data using the Japan Meteorological Agency (JMA) hypocenter, which is located further updip than the USGS/NEIC location. The results are very similar to those presented - the large moment/slip remains in the same region of the fault, but is now adjacent and slightly down-dip of the hypocenter.

The moment rate function has a peak with a value $6.4 \times$ $10^{20} \mathrm{~N} \mathrm{~m} / \mathrm{s}$; a temporal centroid of $75 \mathrm{~s}$, and a seismic moment of $3.6 \times 10^{22} \mathrm{~N} \mathrm{~m}\left(M_{\mathrm{w}} 9.0\right)$, quite compatible with the $\mathrm{W}$-phase solution. The majority of slip in the rupture models is contained in a region approximately $150-\mathrm{km}$ wide by $300-\mathrm{km}$ long, which is relatively compact compared with the $200-\mathrm{km}$ wide, $500-\mathrm{km}$ long aftershock region. The region of substantial slip extends to the trench, and is centered on a segment of the trench that protrudes noticeably more eastward than areas to the north and south. The $M_{\mathrm{w}} 7.7$ normal fault aftershock is located seaward of this bulge in the upper plate and most intraplate trench-slope seismicity is concentrated seaward of the region of large slip. The slip extends about $100 \mathrm{~km}$ to the north and about $200 \mathrm{~km}$ to the south. We recover little slip from deeper portions of the fault model except immediately down dip of the hypocenter. We also recover little slip to the south-southwest in the region of the $M_{\mathrm{w}} 7.9$ aftershock.

\section{Discussion}

A peak slip of 40 meters and a broad region with slip values from 30-40 meters suggests that at least part of this rupture had not failed for three-to-four hundred years or more, possibly back to the historic 869 tsunamigenic earthquake. The long time between such ruptures may explain why an event of this size was not expected in the region, but makes clear the problems geoscientists face when trying to extrapolate imperfect historical and geologic earthquake records to future earthquake forecasts. Recent geodetic work used GPS measured surface velocities to infer strong interseismic coupling along the coast of eastern Japan (Suwa et al., 2006; Loveless and Meade, 2010), landward of where we recover large megathrust slip (off Miyagi prefecture). Our models suggest that the locked region of the megathrust extended farther updip than indicated by the land-based geodetic signals. Resolution of the frictional coupling at the shallowest regions of the trench is an important goal to assess the tsunami potential along subduction boundaries. 
Although our model has its maximum slip downdip from the trench, the slip near the trench is substantial, which helped produce the large observed tsunami. Still, our smooth model and simple mapping of moment to slip using a uniform shear modulus probably underestimates the slip at the shallowest regions of the plate boundary. We compare the model predictions with far-field tsunami observations in Lay et al. (2011b), resolving more details of the slip in this region may require local tsunami observations (e.g. Fujii et al., 2011). One of the important applications of early models of large earthquake slip patterns is to estimate the effects the large earthquake may have on adjacent faults. Recent large earthquake sequences have illuminated the importance of such interactions during great earthquake sequences (Ammon et al., 2008; Lay et al., 2009, 2010a). We refer the reader to Lay et al. (2011c) for a discussion of the implications such large slip may have on processes in adjacent Pacific plate. Finally, an additional intriguing aspect of the model is its difference from short-period teleseismic $P$-wave back projection results that suggest strong short-period $P$-wave radiation occurred along the megathrust, downdip of the hypocenter. Koper et al. (2011) discuss the details of what appears to be a compound rupture with large slow slip and predominantly long period seismic radiation updip and conventional slip with broadband seismic wave radiation downdip.

Acknowledgments. Seismic data were distributed by the IRIS Data Center. Preliminary GPS time series provided by the ARIA team at JPL and Caltech. All original GEONET RINEX data provided to Caltech by the Geospatial Information Authority (GSI) of Japan. We also thank Luis Rivera for sharing his normal mode summation software and Gavin Hayes for discussions. This work was supported by NSF grant EAR0635570, AFRL Contract FA8718-09-C-007, and Award Number 05HQGR0174. Comments from J. Loveless, K. Yomogida, and K. Koketsu helped improve this manuscript.

\section{References}

Ammon, C. J., A. A. Velasco, and T. Lay, Rapid estimation of rupture directivity-Application to the 1992 Landers (Ms = 7.4) and Cape Mendocino $(\mathrm{Ms}=7.2)$, California earthquakes, Geophys. Res. Lett., 20, 97 $100,1993$.

Ammon, C. J., C. Ji, H.-K. Thio, D. Robinson, S. Ni, V. Hjorleifsdottir, H. Kanamori, T. Lay, S. Das, D. V. Helmberger, G. Ichinose, J. Polet, and D. Wald, Rupture process of the great 2004 Sumatra-Andaman earthquake, Science, 308, 1133-1139, 2005.

Ammon, C. J., H. Kanamori, T. Lay, and A. A. Velasco, The 17 July 2006 Java tsunami earthquake, Geophys. Res. Lett., 233, L234308, doi:10.10239/2006GL028005, 2006.

Ammon, C. J., H. Kanamori, and T. Lay, A great earthquake doublet and seismic stress transfer cycle in the central Kuril islands, Nature, 451, 561-566, 2008.

DeMets, C., R. G. Gordon, and D. F. Argus, Geologically current plate motions, Geophys. J. Int., 181, 1-80, doi:10.1111/j.1365-246X. 2009.04491.x, 2010.

Fujii, Y., K. Satake, S. Sakai, M. Shinohara, and T. Kanazawa, Tsunami source of the 2011 off the Pacific coast of Tohoku Earthquake, Earth Planets Space, 63, this issue, 815-820, 2011.

Furlong, K. P., T. Lay, and C. J. Ammon, A great earthquake rupture across a rapidly evolving three-plate boundary, Science, 324, 226-229, 2009.

Ji, C., D. J. Wald, and D. V. Helmberger, Source description of the 1999 Hector Mine, California, earthquake; Part I, Wavelet domain inversion theory and resolution analysis, Bull. Seismol. Soc. Am., 92, 1192-1207, 2002 .

Kanamori, H. and L. Rivera, Source inversion of W-phase: speeding up seismic tsunami warning, Geophys. J. Int., 175, 222-238, 2008.

Kikuchi, M. and H. Kanamori, Inversion of complex body waves, Bull. Seismol. Soc. Am., 72, 491-506, 1982.

Koper, K. D., A. R. Hutko, T. Lay, C. J. Ammon, and H. Kanamori, Frequency-dependent rupture process of the $2011 M_{\mathrm{w}} 9.0$ Tohoku Earthquake: Comparison of short-period $P$ wave backprojection images and broadband seismic rupture models, Earth Planets Space, 63, this issue, 599-602, 2011.

Lay, T., H. Kanamori, C. J. Ammon, A. R. Hutko, K. Furlong, and L. Rivera, The 2006-2007 Kuril Islands great earthquake sequence, J. Geophys. Res., 114, B113208, doi:10.1029/2008JB006280, 2009.

Lay, T., C. J. Ammon, H. Kanamori, L. Rivera, K. Koper, and A. R. Hutko, The 29 September 2009 Great Samoa earthquake, Nature, 466, 964 968, doi:10.1038/nature09214, 2010a.

Lay, T., C. J. Ammon, H. Kanamori, K. D. Koper, O. Sufri, and A. R. Hutko, Teleseismic inversion for rupture process of the 27 February 2010 Chile (Mw 8.8) earthquake, Geophys. Res. Lett., 37, L13301, doi:10.1029/2010GL043379, 2010b.

Lay, T., C. J. Ammon, A. R. Hutko, and H. Kanamori, Effects of kinematic constraints on teleseismic finite-source rupture inversions: Great Peruvian earthquakes of 23 June 2001 and 15 August 2007, Bull. Seismol. Soc. Am., 100, 969-994, doi:10.1785/0120090274, 2010c.

Lay, T., C. J. Ammon, H. Kanamori, L. Xue, and M. J. Kim, Possible large near-trench slip during the $2011 M_{\mathrm{w}} 9.0$ off the Pacific coast of Tohoku Earthquake, Earth Planets Space, 63, this issue, 687-692, 2011a.

Lay, T., Y. Yamazaki, C. J. Ammon, K. F. Cheung, and H. Kanamori, The $2011 M_{\mathrm{w}} 9.0$ off the Pacific coast of Tohoku Earthquake: Comparison of deep-water tsunami signals with finite-fault rupture model predictions, Earth Planets Space, 63, this issue, 797-801, 2011 b.

Lay, T., C. J. Ammon, H. Kanamori, M. J. Kim, and L. Xue, Outer trenchslope faulting and the $2011 M_{\mathrm{w}} 9.0$ off the Pacific coast of Tohoku Earthquake, Earth Planets Space, 63, this issue, 713-718, 2011c.

Loveless, J. P. and B. J. Meade, Geodetic imaging of plate motions, slip rates, and partitioning of deformation in Japan, J. Geophys. Res., 115, B02410, doi:10.1029/2008JB006248, 2010.

Suwa, Y., S. Miura, A. Hasegawa, T. Sato, and K. Tachibana, Interplate coupling beneath NE Japan inferred from three-dimensional displacement field, J. Geophys. Res., 111, B04402, doi:10.1029/2004JB003203, 2006.

C. J. Ammon (e-mail: charlesammon@psu.edu), T. Lay, H. Kanamori, and M. Cleveland 